\title{
Synthesis and Chemical Modification of Maleic Anhydride Copolymers with 2-Amino Ethyl Benzoate Groups
}

\author{
Mohammad Hossein Nasirtabrizi*, Seid Jafar Mousavi \\ Department of Applied Chemistry, Ardabil Branch, Islamic Azad University, Ardabil, Iran \\ *E-mail address: nasirtabrizi@gmail.com, Corresponding author: Tel.: + 989143544172
}

Received: 30 September 2018, Revised: 21 October 2018, Accepted: 15 November 2018

\begin{abstract}
A B S T R A C T
Maleic anhydride (MAN) copolymers with methyl methacrylate, ethyl methacrylate, methyl acrylate, ethyl acrylate, and butyl acrylate monomers at 1:3 mole ratios were synthesized by free radical polymerization in the presence of azobis(isobutyronitrile) as initiator and dry ethyl acetate as solvent. Copolymer compositions were obtained using the related proton nuclear magnetic resonance ( $\left.{ }^{1} \mathrm{HNMR}\right)$ spectra, and the polydispersity of the copolymers was determined by gel permeation chromatography. Then, a solution of 2amino ethyl benzoate salt as a nucleophilic reagent reacted through the ring opening of anhydride groups in copolymers resulting to modified copolymers $I_{a b}$ to $V_{a b}$. All the prepared polymers were characterized by Fourier transform Infrared and 1 HNMR spectroscopic techniques. The glass transition temperature (Tg) of all copolymers before and after modification was determined by dynamic mechanical thermal analysis (DMTA). It was shown that the chemical modification of MAN copolymers with 2-amino ethyl benzoate substituents as side chains decreased the free volume of the polymers, and therefore, the rigidity and $\mathrm{Tg}$ is increased.
\end{abstract}

Keywords: Chemical modification, Infrared spectra, Dynamic mechanical thermal analysis (DMTA), Thermo-gravimetric analysis (TGA), Maleic anhydride (MAN) copolymers.

\section{GRA P H I C A L ABS TRACT}

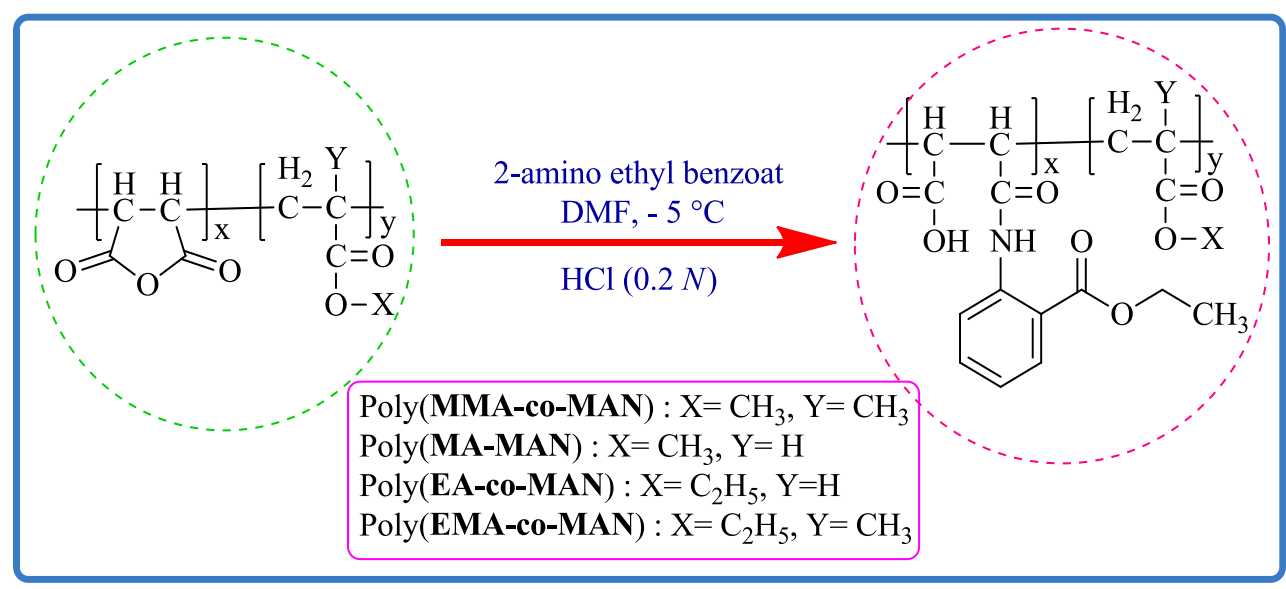




\section{Introduction}

The mid-nineteenth century saw the first successful attempts to modify polymers in a useful way. The nitration of cellulose was reported in 1833 and Goodyear's vulcanization process was patented in 1844 [1-4]. Celluloid was in common use by the end of the century and could be said to be the first synthetics, or at least partly synthetic plastic. Since then the scope of application of many polymers, both natural and synthetic, has been widened by suitable chemical modification [5]. The prime aim of the chemical modification has been to produce materials with new and improved properties and many such materials are now produced in commercial quantities. The technical importance of many chemically modified polymers has stimulated research at a fundamental level.

The chemistry of heterocyclic compounds has been an interesting field of study for a long time. The synthesis of novel Maleic anhydride (MAN) copolymers modified with any groups and it's derivatives and investigation of their chemical and mechanical behavior have gained more importance in recent decades for chemical industries, medicinal and agricultural reasons. The thermal stability of polymers closely relates to molecular structures, and a detailed analysis of thermal transitions pro-vides additional insight in the molecular arrangement of complex copolymers. In order to get a better insight in the thermal transitions thermogravimetric analysis (TGA) are traditionally used, The copolymerization of maleic anhydride and then it's modification with amino ethyl benzoate groups provides good physiochemical properties with high polarity,rigidity, glass transition temperature, and functionality. Maleic anhydride (MAN) is an excellent monomer which can provide interest copolymers, and that it can homo polymerize by a radical polymerization condition [6-10].

In this work, we explored the polymerization of Maleic anhydride (MAN) copolymers, with some monomers( such as methyl methacrylate (MMA), ethyl methacrylate (EMA), methyl acrylate (MA), ethyl acrylate (EA), and butyl acrylate (BA) and then resulted polymers have been modified by using of 2-amino ethyl benzoate groups. All the prepared polymers were characterized by Fourier transform infrared, dynamic mechanical thermal analysis (DMTA) and ${ }^{1}$ HNMR spectroscopic techniques. The glass transition temperature $(\mathrm{Tg})$ of all copolymers before and after modification was determined by dynamic mechanical thermal analysis (DMTA).

\section{Experimental}




\subsection{Materials}

2-amino ethyl benzoate, methyl methacrylate (MMA), ethyl meth-acrylate (EMA), methyl acrylate (MA), ethylacrylate (EA), and butyl acrylate (BA) (Merck, Whitehouse Station, NJ, USA) were distilled under reduced pressure to remove inhibitors before use. Maleic anhydride (Aldrich, St. Louis, MO, USA) was recrystallized from chloroform. Ethyl acetate was stirred over calcium hydride for $24 \mathrm{~h}$ and distilled in argon atmosphere. The radical initiator of azobis (isobutyronitrile) (AIBN; Merck) was purified by crystallization from methanol. Sodium hydride (60\%) was obtained from Aldrich. $N, N$-Dimethyl form amide (DMF) was dried over anhydrous $\mathrm{MgSO} 4$ for 2 days and later with phosphine anhydride overnight. After drying, DMF was distilled under reduced pressure.

\subsubsection{General procedure for solubility}

The polymer $(0.1 \mathrm{~g})$ and solvent $(10 \mathrm{ml})$ were placed in an airtight vial and agitated about $25^{\circ} \mathrm{C}$ for $1 \mathrm{~h}$. The samples were considered to be soluble if a singlephase, clear, gel free solution was observed. This procedure was carried out again with the same condition as mentioned but for a much longer time (overnight) using a shaker.

The resulting copolymers I to V were soluble in ethyl acetate, N,Ndimethylformamide, and dimethylsulfoxide and insoluble in nhexane, chloroform, tetrahydrofuran, and hydroxyl group-containing solvents such as methanol, ethanol, or water.

\subsubsection{Preparation of MAN copolymers}

The MAN monomer was copolymerized with methyl methacrylate, ethyl methacrylate, methyl acrylate, ethyl acrylate, and butyl acrylate monomers in ethyl acetate at $70^{\circ} \mathrm{C} \pm 1^{\circ} \mathrm{C}$ using AIBN as the radical polymerization initiator.For simplicity, we have labeled the obtained copolymers by numbers from one to five (I to V). Copolymerization of maleic anhydride with methacrylate and acrylate monomers poly(MAN-co-MMA) (I), poly(MAN-co-EMA) (II), poly(MAN-co-MA) (III), poly(MAN-co-EA) (IV), and poly(MAN-co-BA) (V) were synthesized based on the following general procedure: In five different Pyrex glass ampoules, a mixture of $1.96 \mathrm{~g}$ ( $20 \mathrm{mmol}$ ) of MAN, 0.065 $\mathrm{g}(0.4 \mathrm{mmol})$ of AIBN, and $2.00 \mathrm{~g}(20 \mathrm{mmol})$ of methyl meth- acrylate, $2.28 \mathrm{~g}(20 \mathrm{mmol})$ of ethyl methacrylate, $1.73 \mathrm{~g}(20 \mathrm{mmol})$ of methyl acrylate, $2.00 \mathrm{~g}$ ( $20 \mathrm{mmol})$ of ethyl acrylate, or $2.56 \mathrm{~g}(20 \mathrm{mmol})$ of butyl acrylate was dissolved in $15 \mathrm{ml}$ of dry ethyl acetate, respectively. Then, the ampoules were degassed, sealed under vacuum condition, and maintained at $70^{\circ} \mathrm{C} \pm 1^{\circ} \mathrm{C}$ in 
a water bath and shaken using a shaker for about $24 \mathrm{~h}$. Then, the viscous solutions were poured from the ampoules into 150 $\mathrm{ml}$ of cooled methanol separately. The precipitates were collected and washed with methanol for several times and dried under vacuum at room temperature to give $3.1 \mathrm{~g}$ of copolymer I, $3.39 \mathrm{~g}$ of copolymer II, $3.07 \mathrm{~g}$ of copolymer III, $3.1 \mathrm{~g}$ of copolymer IV, and $3.38 \mathrm{~g}$ of copolymer V (Table 4, Figure 4a).

\subsubsection{Preparation of sodium 2 -amino Ethyl benzoate salt}

For preparing sodium 2-amino ethyl benzoate, sodium hydride ( $4 \mathrm{mmol}, 0.096$ g) was slowly added to 2-amino ethyl benzoate ( $4 \mathrm{mmol}, 1 \mathrm{~g}$ ) dissolved in $15 \mathrm{ml}$ of DMF at room temperature. Then, the mixture was stirred under nitrogen atmosphere for $30 \mathrm{~min}$.

\subsubsection{Modification}

Attaching 2-amino ethyl benzoate groups to copolymers (I to V) poly(MAN-co-MMA), poly(MAN-co-EMA), poly(MAN-co-MA), poly(MAN-co-EA) and poly(MAN-co-BA) containing 2-amino ethyl benzoate groups were prepared as follows:

In a 100-ml two-necked round-bottom flask equipped with a dropping funnel, a solution of sodium 2-amino ethyl benzoate in DMF (15 ml) was prepared.
After this time, the mixture was cooled to $-5^{\circ} \mathrm{C}$ in an ice-salt mixture under vigorous stirring. A solution of copolymer I (0.198 g, $2 \mathrm{mmol})$, copolymer II (0.230 g, 2 mmol), copolymer III (0.200 g, $2 \mathrm{mmol})$, copolymer IV (0.230 g, $2 \mathrm{mmol})$, or copolymer V (0.226 g, $2 \mathrm{mmol}$ ) in DMF (15 $\mathrm{ml}$ ) was prepared and transferred into the dropping funnel under argon atmosphere.

Then, a solution of copolymers (I to V) was added dropwise with stirring to the solution of sodium 2-amino ethyl benzoate into the flask at $-5^{\circ} \mathrm{C}$ within $1 \mathrm{~h}$. The reaction mixture was kept at $-5^{\circ} \mathrm{C}$ temperature for another $3 \mathrm{~h}$ under stirring. Then, the solution was poured into an excess cold $\mathrm{HCl}(0.2 N)$, and the white precipitate was filtered and washed with $\mathrm{HCl}(0.2 N)$. The resulting polymer was washed sequentially with $\mathrm{NaOH}(0.2 N)$ and water $(50 \mathrm{ml})$. Finally, the obtained white polymers containing 2-amino ethyl benzoate substituents in the Side chains were collected and dried under vacuum at room temperature (Figure 4c). The yields of modified copolymers are presented in Table 1.

Note: the resulted copolymers after reaction with azobis (isobutyronitrile) as initiator have been labeled by $\mathrm{I}_{\mathrm{ab}}$ to $\mathrm{V}_{\mathrm{ab}}$ and the obtained polymers after modification have been labeled by $I_{\text {pht }}$ to $V_{\text {pht }}$. 
Table 1. The result of reaction between $2 \mathrm{mmol}$ of each polymers (I to $\mathrm{V}$ ) with ab

\begin{tabular}{cccc}
\hline Modified copolymer & Weight $(\mathrm{g})$ & Yield $(\%)$ & $\mathrm{Tg}\left({ }^{\circ} \mathrm{C}\right)$ \\
\hline $\mathrm{I}_{\mathrm{Pht}}$ & 0.68 & 89 & 120 \\
$\mathrm{II}_{\mathrm{Pht}}$ & 0.72 & 91 & 133 \\
III $_{\mathrm{Pht}}$ & 0.65 & 85 & 85 \\
IV $_{\mathrm{Pht}}$ & 0.66 & 87 & 96 \\
$\mathrm{~V}_{\mathrm{Pht}}$ & 0.60 & 76 & 102 \\
\hline
\end{tabular}

\subsection{Instruments}

Infrared spectra were recorded using a Bruker-IR Scientific spectrophotometer as $\mathrm{KBr}$ pellets (Madison, WI, USA). ${ }^{1} \mathrm{HNMR}$ spectra were run on a Bruker $250 \mathrm{MHz}$ spectrometer at room temperature using deuterated dimethyl sulfoxide (DMSO-d6) as solvent. The molecular weights (Mw and $\mathrm{Mn}$ ) were determined using a Waters 501 gel permeation chromatograph fitted with 103-nm Water-Styren gel columns (Milford, MA, USA). Tg was determined using Tritec 2000 DMA (Triton Technology, Ltd., Keyworth, UK) at a heating rate of $5^{\circ} \mathrm{C} / \mathrm{min}$ in air.

\section{Results and discussion}

\subsection{Molecular weights}

The number and weight average molecular weights $(\mathrm{Mn}$ and $\mathrm{Mw}$, respectively) and polydispersity index of copolymer samples were determined by gel permeation chromatography and are presented in Table 2.

\subsection{Copolymer composition}

In the past few decades, ${ }^{1}$ HNMR spectroscopic analysis has been established as a powerful tool for the determination of copolymer compositions because of its simplicity, rapidity, and sensitivity [9-11]. The copolymer compositions were calculated by the ${ }^{1}$ HNMR spectral data (Table3).

The compositions of copolymers synthesized using various monomer feed ratios were determined by the ${ }^{1} \mathrm{HNMR}$ method and were achieved by comparing the integrals of the maleic anhydride, methyne,and methoxy group regions in the spectra of the commoner units $\left(\mathrm{m}_{1}\right.$ and $\left.\mathrm{m}_{2}\right)$ in copolymers using ${ }^{1} \mathrm{HNMR}$ analysis data that were calculated according to the following equations:

$$
\frac{A m_{1}(C H)}{A_{\text {total }}}=\frac{n_{1} m_{1}}{a_{1} m_{1}+a_{2} m_{2}}
$$

$\frac{\mathrm{Am}_{2}\left(\mathrm{OCH}_{3} \text { or } \mathrm{OCH}_{2}\right)}{A_{\text {total }}}=\frac{n_{2} m_{2}}{a_{1} m_{1}+b_{2} m_{2}}$ (Eq. 2) $m_{1}+m_{2}=1$

where $A m_{1}$ and $A m_{2}$ are the normalized are as per $\mathrm{H}$ from the corresponding functional groups of the monomer unit 
regions in ${ }^{1} \mathrm{HNMR}$ spectra, $\mathrm{A}_{\text {total }}$ is the total area of pro- tons in the copolymer, $\mathrm{n}_{1}$ and $\mathrm{n}_{2}$ are the integers of proton (s) in the functional group of the monomers, and a and $b$ are integers of protons in the monomer units $\left(\mathrm{m}_{1}\right.$ and $\left.\mathrm{m}_{2}\right)$. Monomer unit ratios can be calculated from Equations 1 and 2 using the following simplified formula:

$\frac{m_{1}}{m_{2}}=\frac{n_{2} A m_{1}(\mathrm{CH})}{\left.n_{1} \mathrm{Am}_{2} \mathrm{OCH}_{3} \text { or } \mathrm{OCH}_{2}\right)} \quad$ (Eq.4)

\subsection{Infrared and ${ }^{1}$ HNMR spectra}

Infrared and ${ }^{1} \mathrm{HNMR}$ spectra for copolymers before and after the modification were recoded and investigated. The Figures (1) to (15) are shown in supplementary data and their commentaries are recorded in Table 4. But due to some reasons the spectra of copolymer IV is not available

Table 2. Molecular weights and Tg of MAN copolymers

\begin{tabular}{ccccc}
\hline Polymer & Mw (103) & Mn (103) & $\mathrm{Mw} / \mathrm{Mn}$ & $\operatorname{Tg}\left({ }^{\circ} \mathrm{C}\right)$ \\
\hline I & 37.4 & 19.35 & 1.94 & 77.3 \\
II & 39.2 & 19.8 & 1.97 & 94 \\
III & 28 & 15.5 & 1.8 & 36 \\
IV & 32.1 & 16.05 & 2.0 & 39 \\
V & 47 & 24.73 & 1.9 & 52 \\
\hline
\end{tabular}

Table 3. The molar composition of copolymers (I to V)

\begin{tabular}{ccccccc}
\hline Polymer & $\begin{array}{c}\text { MAN } \\
(\mathrm{mol} \%)\end{array}$ & $\begin{array}{c}\text { MMA } \\
(\mathrm{mol} \%)\end{array}$ & $\begin{array}{c}\text { EMA } \\
(\mathrm{mol} \%)\end{array}$ & $\begin{array}{c}\text { MA } \\
(\mathrm{mol} \%)\end{array}$ & $\begin{array}{c}\text { EA } \\
(\mathrm{mol} \%)\end{array}$ & $\begin{array}{c}\text { BA } \\
(\mathrm{mol} \%)\end{array}$ \\
\hline I & 45 & 45 & - & - & - & - \\
II & 45 & - & 55 & - & - & - \\
III & 38 & - & - & 62 & - & - \\
IV & 45 & - & - & - & 55 & - \\
V & 39 & - & - & - & - & 61 \\
\hline
\end{tabular}

Table 4. The commentaries of Infrared and ${ }^{1}$ HNMR spectra for copolymers before and after the modification.

\begin{tabular}{|c|c|c|}
\hline Compound & FT-IR spectra & $\begin{array}{l}{ }^{1} \text { HNMR spectra } \\
\text { (in Chloroform) }\end{array}$ \\
\hline $\begin{array}{l}\text { Copolymer I } \\
\text { (MAN-MMA) }\end{array}$ & $\begin{array}{l}\text { Stretching vibration of } \mathrm{C}=0 \text { ester has } \\
\text { appeared in } 1729 \mathrm{~cm}^{-1} \text { and stretching }\end{array}$ & $\begin{array}{l}3 \mathrm{H} \text {, in } \mathrm{CH}_{3} \text { related to main chain of } \\
\text { copolymer has appeared in: }(0.75\end{array}$ \\
\hline
\end{tabular}


vibration of $\mathrm{C}=0$ Maleic anhydride has appeared in 1783 and1856 cm-1.and appeared bands in 1019 and $1090 \mathrm{~cm}^{-}$ ${ }^{1}$ was related to asymmetric stretching vibration of C-0 for Anhydride ring, and appeared bands in 699 and $764 \mathrm{~cm}^{-1}$ was related to Bending vibration of $\mathrm{C}-\mathrm{H}$ for Anhydride ring, C-O ester: 11150 and $1242 \mathrm{~cm}^{-1}$ ), Aliphatic C-H: (2955 and2997 $\mathrm{cm}^{-1}$ ),Bending vibration of methylene group: $\left(1450 \mathrm{~cm}^{-1}\right)$.

Copolymer I

(MAN-MMA)

after modification with 2-amino ethyl benzoate groups

Copolymer II (MAN- EMA)

Copolymer II (MAN- EMA) after modification with 2 -amino ethyl benzoate groups

Copolymer III (MAN- MA)

Copolymer III

(MAN-MA)

after modification with 2 -amino ethyl benzoate groups
Stretching vibration of $\mathrm{C}=0$ Maleic anhydride in 1783 and1856 $\mathrm{cm}^{-1}$ was disappeared, Aliphatic C-H: $\left(2995 \mathrm{~cm}^{-1}\right)$, $\mathrm{C}=0$ ester: $\left(1623 \mathrm{~cm}^{-1}\right), \mathrm{C}=0$ Aromatic ring: $\left(1469 \mathrm{~cm}^{-1}\right)$.

$\mathrm{C}=0$ ester: $\left(1729 \mathrm{~cm}^{-1}\right), \mathrm{C}=0$ Maleic anhydride: (1784 and $1855 \mathrm{~cm}^{-1}$ ), C-O Anhydride ring: $\left(1026 \mathrm{~cm}^{-1}\right), \quad \mathrm{C}-\mathrm{H}$ Anhydride ring: (593 and763 $\mathrm{cm}^{-1}$ ), C-O ester: (1153 and $1244 \mathrm{~cm}^{-1}$ ), Aliphatic C$\mathrm{H}$ : (2999 and $\left.2953 \mathrm{~cm}^{-1}\right)$.

The bands related to $\mathrm{C}=0$ Maleic anhydride in(1784 and $1855 \mathrm{~cm}^{-1}$ ) was disappeared, Aliphatic C-H : $\left(1497 \mathrm{~cm}^{-1}\right)$, $\mathrm{C}=0$ Aromatic ring: $\left(1677 \mathrm{~cm}^{-1}\right)$,a broad band that it was related to presence of acidic hydroxyl groups in the polymer chains has appeared in $3457 \mathrm{~cm}^{-1}$, this broad band is represents the ring opening reaction in the base polymers.

$\mathrm{C}=0$ ester: $\left(1733 \mathrm{~cm}^{-1}\right), \mathrm{C}=0$ Maleic anhydride: (1787 and $1847 \mathrm{~cm}^{-1}$ ), C-O Anhydride ring: (1101 and $\left.1043 \mathrm{~cm}^{-1}\right), \mathrm{C}-$ $\mathrm{H}$ Anhydride ring: (696 and $760 \mathrm{~cm}^{-1}$ ), C0 ester: (1165 and 1261), Aliphatic C-H: (2960 and $3007 \mathrm{~cm}^{-1}$ ).

Aliphatic C-H : $\left(2932 \mathrm{~cm}^{-1}\right), \mathrm{C}=\mathrm{O}$ ester: (1680 $\left.\mathrm{cm}^{-1}\right), \mathrm{C}=\mathrm{O}$ aromatic ring: (1499 $\mathrm{cm}^{-1}$ ), a broad band that it was related to presence of acidic hydroxyl groups in the polymer chains has appeared in $3455 \mathrm{~cm}^{-}$ 1 , this broad band is represents the ring opening reaction in the base polymers. to $1.27 \mathrm{ppm}), 2 \mathrm{H}$, in $-\mathrm{CH}_{2}$-c: (1.87 to 2.47), Methine protons of anhydride groups in: (3.54 ppm), and Three Methyl protons of $\mathrm{COOCH}_{3}$ related to methyl methacrylate has appeared in: (3.31 ppm).

Protons of aromatic ring has appeared in: (7 to $8 \mathrm{ppm}), 2 \mathrm{H}$, in $\mathrm{CH}_{2}$-c ester: (4.36 ppm), $3 \mathrm{H}$, in CH3: (0 to $1 \mathrm{ppm}$ ).

$3 \mathrm{H}$, in $\mathrm{CH}_{3}$ related to main chain of copolymer has appeared in: (0.7 to $1.17 \mathrm{ppm}$ ), $2 \mathrm{H}$, in $-\mathrm{CH}_{2}-\mathrm{C}$ : (1.9 to $2.26 \mathrm{ppm})$, Methine protons of anhydride groups in: (4 ppm), and Three Methyl protons of $-\mathrm{COOCH}_{3}$ related to Ethyl methacrylate has appeared in: (3.72 ppm).

$\mathrm{H}$ in C-H Anhydride: (4 ppm), $3 \mathrm{H}$, in $\mathrm{CH}_{3}$ related to Carbonyl group of Ethyl 2-amino-benzoic acid has appeared in: (2.98 ppm), H, in ArCH: (7 to $8 \mathrm{ppm}$ ).

$2 \mathrm{H}$, in $-\mathrm{CH}_{2}-\mathrm{C}$ and $\mathrm{H}$ in $\mathrm{CH}$ has appeared in: (1.58 to $2.85 \mathrm{ppm}$ ), Methine protons of anhydride groups in: (3.84 ppm), $3 \mathrm{H}$ in $\mathrm{COOCH}_{3}$ ester: (3.63 ppm).

The peaks in (7 to $8 \mathrm{ppm}$ ) are related to Aromatic ring that they are Indicated to Poor absorption, The peaks in $(7.28 \mathrm{ppm})$ are related to impurities of chloroform, and the peaks in $(8.02$ ppm) are related to impurities of DMF. 
$\mathrm{C}=0$ ester: $\left(1728 \mathrm{~cm}^{-1}\right), \quad \mathrm{C}=0$ Maleic anhydride: (1788 and $1855 \mathrm{~cm}^{-1}$ ), C-H Anhydride ring: (600 and $746 \mathrm{~cm}^{-1}$ ), C-O ester: (1154 and $1391 \mathrm{~cm}^{-1}$ ), Aliphatic C$\mathrm{H}:\left(2961 \mathrm{~cm}^{-1}\right)$.

Aliphatic C-H:(2932 $\left.\mathrm{cm}^{-1}\right), \mathrm{C}=\mathrm{O}$ related to COOH group: (1679 $\left.\mathrm{cm}^{-1}\right)$, a broad band that it was related to presence of acidic hydroxyl groups in the polymer chains has appeared in $3461 \mathrm{~cm}^{-1}$, this broad band is represents the ring opening reaction in the base polymers.
The peaks in (7 to $8 \mathrm{ppm}$ ) are related to Aromatic ring that they are Indicated to Poor absorption, The peaks in (7.36 ppm) are related to impurities of chloroform, and the peaks in (8.42 ppm) are related to impurities of DMF.

$\mathrm{H}$ in C-H Anhydride: (4 ppm), that due to the space prohibitions, some of Anhydride rings can't reacted with Ethyl 2-aminobenzoic acid.

\subsection{Glass transition temperature} analysis

The thermal behavior of all the copolymers was investigated by DMTA. The glass transition temperature of MAN copolymers with methacrylate monomers is higher than that of MAN copolymers with acrylate monomers since the $\alpha$-methyl group in the main chain of methacrylate copolymers has reduced the flexibility of the polymer chains and so the $\mathrm{Tg}$ has increased.

The modification of copolymers with 2amino ethyl benzoate the maleic anhydride functional group which grafts on the copolymers' backbone acts as the chemical link between the anhydride group and the sodium 2-amino ethyl benzoate in a nucleophilic substitution reaction. Copolymers of MAN are receiving great attention due to the presence of a reactive anhydride ring, which offers it an opportunity to enter into a wide range of chemical reactions. The anhydride group possesses a higher reactivity for phthalimide even though this coupling reaction is very rapid at $-5^{\circ} \mathrm{C}$. A solution of 2-amino ethyl benzoate salt as a nucleophilic reagent reacted with anhydride groups in copolymers I to $\mathrm{V}$ with a ring opening of all anhydride groups to give new modified copolymers. These new modified copolymers $\mathrm{I}_{\mathrm{ab}}$ to $\mathrm{V}_{\mathrm{ab}}$ were isolated in high yields at distilled $\mathrm{HCl}(0.2$ $N$ ) as a non-solvent. Compared to the previous coupling methods for the preparation of modified copolymers of maleic anhydride in the literature [11], the present method is simple the coupling reaction is fast.

Although the methods of 2-amino ethyl benzoate connection to initial copolymers 
and their modification has been carried out using similar methods that we have worked previously [9], 2-amino ethyl benzoate connection has been done in the present paper for the first time. The ringopening reaction of maleic anhydride copolymer at low temperature $\left(-5^{\circ} \mathrm{C}\right)$ is attempted for the first time in our research group.

The thermal behavior of all the copolymers was investigated by DMTA. DMTA analysis showed that the presence of 2-amino ethyl benzoate led to an increase in $\mathrm{Tg}$ from $92^{\circ} \mathrm{C}$ for copolymer I to $120^{\circ} \mathrm{C}$ for copolymer $\mathrm{I}_{\mathrm{ab}}$, from $94^{\circ} \mathrm{C}$ for copolymer II to $133{ }^{\circ} \mathrm{C}$ for copolymer $\mathrm{II}_{\mathrm{ab}}$, to $85^{\circ} \mathrm{C}$ for copolymer III $_{a b}$, from $39^{\circ} \mathrm{C}$.

Also the conditions of preparation of polymers (I to $\mathrm{V}$ ) at $70^{\circ} \mathrm{C}$ are recorded in Table 5.

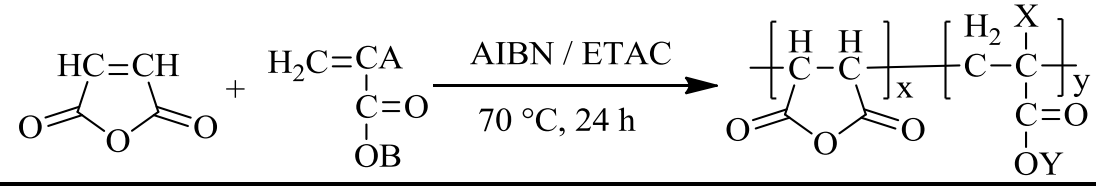

Scheme 1. Preparation of MAN copolymers

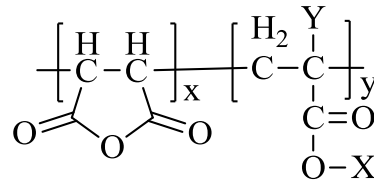

1. 2-amino ethyl benzoat DMF, $-5^{\circ} \mathrm{C}$

2. $\mathrm{HCl}(0.2 \mathrm{~N})$

Poly(MMA-co-MAN) : $\mathrm{X}=\mathrm{CH}_{3}, \mathrm{Y}=\mathrm{CH}_{3}$ Poly(MA-MAN) : $\mathrm{X}=\mathrm{CH}_{3}, \mathrm{Y}=\mathrm{H}$

Poly(EA-co-MAN) : $\mathrm{X}=\mathrm{C}_{2} \mathrm{H}_{5}, \mathrm{Y}=\mathrm{H}$

Poly(EMA-co-MAN) : $\mathrm{X}=\mathrm{C}_{2} \mathrm{H}_{5}, \mathrm{Y}=\mathrm{CH}_{3}$

Scheme 2. Ring opening of anhydride groups to new modified copolymers synthesis.

Table 5. The conditions of preparation of polymers (I to $\mathrm{V}$ ) at $70^{\circ} \mathrm{C}$

\begin{tabular}{cllccccc}
\hline Sample & Monomer1 & Monomer2 & $\begin{array}{c}\text { Amount of } \\
1(\mathrm{mmol})\end{array}$ & $\begin{array}{c}\text { Amount of } \\
2(\mathrm{mmol})\end{array}$ & $\begin{array}{c}\text { Time } \\
(\mathrm{h})\end{array}$ & $\begin{array}{c}\text { Weight } \\
(\mathrm{g})\end{array}$ & $\begin{array}{c}\text { Yield } \\
(\%)\end{array}$ \\
\hline I & MAN & MMA & 20 & 20 & 24 & 3.1 & 78 \\
II & MAN & EMA & 20 & 20 & 24 & 3.39 & 80 \\
III & MAN & MA & 20 & 20 & 24 & 3.07 & 83 \\
IV & MAN & EA & 20 & 20 & 24 & 3.1 & 78 \\
V & MAN & BA & 20 & 20 & 24 & 3.38 & 75
\end{tabular}




\section{Conclusions}

We have detailed the preparation and characterization of novel MAN copolymers bearing 2-amino ethyl benzoate groups of side chain substituents. The work described in this paper deals with the nucleophilic ring opening of anhydrides by 2-amino ethyl benzoate groups. The copolymers of MAN with different methacrylate and acrylate monomers were synthesized by free radical solution polymerization. The molar compositions of the obtained copolymers were calculated by the corresponding ${ }^{1} \mathrm{HNMR}$ analysis. The anhydride group possessed a higher reactivity for the 2-amino ethyl benzoate in the modification process. Comparison of the ${ }^{1}$ HNMR and IR spectra of copolymers before and after modification showed disappearance of the peaks assigned to the anhydride ring and appearance of a new peak characteristic of 2-amino ethyl benzoate moieties, thus proving the modification of MAN copolymers. The MAN copolymers prepared here should be useful for the construction of well-defined functional polymers. DMTA indicated that the $\mathrm{Tg}$ of copolymers increases with incorporation of bulky 2-amino ethyl benzoate groups in side chains of MAN units. The presence of the 2-amino ethyl benzoate groups in the polymer structure reduces the free volume of macromolecules with modification of their properties and applications.

\section{References}

[1]. K.D. Safa, H.A. Eram, M.H. Nasirtabrizi, Iran. Polym. J. , 2006, $15,1249-1257$

[2]. H. Duan, T. Qiu, L. Guo, J. Ye, Yuan, X. Li. Int. J. Adhes. Adhes, 2016, 66, 138-146.

[3]. E.A. Ali, S.S. Elkholy, R.E. Morsi, M.Z. Elsabee. J. Taiwan. Inst. Chem. Eng., 2016, 64, 325-335

[4]. J. Zhou, L.I. Wang, C.H. Wang, T. Chen, H. Yu, Q. Yang, J. Polymer, 2005, 46, 1157-1164.

[5]. R. Nieuwhof, A. Marcelis, E. Sudholter, J. Macromol., 1999, 32, 1398-1406.

[6]. P. Wongthong, C. Nakason, Q. Pan, G. L. Rempel, S. Kiatkamjornwong, Polymer J., 2013, 49, 4035-4046.

[7]. K. Wang, W. Huang, P. Xia, C. Gao, D. Yan, React. Funct. Polym., 2002, 52, 143-148.

[8]. D.J. Liaw, C.H. Tsai, J. Mol. Cat. A: Chem., 1999, 147, 23-31.

[9]. M.H. Nasirtabrizi, Z.M. Ziaie, A. Parchehbaf Jadid, J. Iran. Chem. Res., 2011, 4, 59-68.

[10]. H. Kesim, Z. Rzeav, S. Pincer, E. Piskin, Polymer, 2003, 44, 2897 2909.

[11]. F.A. Nicolescu, V.V. Jerca, A.M. Albu, D.M. Vuluga, D.S. Vasilescu, U. P. B. Sci. Bull., 2009, 71, 1454-2331. 